ISSN 1112-9867

\title{
BODY FAT AND RISK OF CARDIOVASCULAR DISEASES AMONG THE TAMIL SCHOOL TEACHERS IN KUALA SELANGOR, SELANGOR
}

\author{
G. Elumalai*, A. Hashim, M. I. Shahril, N. Salimin and F. Hossein Abadi \\ Faculty of Sports Science and Coaching, Universiti Pendidikan Sultan Idris, Tg Malim, Perak, \\ Malaysia
}

Published online: 10 November 2017

\begin{abstract}
This quantitative survey aims to measure the overall body fat, BMI, abdominal fat and the risk of cardiovascular diseases among 60 Tamil school teachers from Kuala Selangor District, Selangor. The subjects voluntarily participated in this study. The total body fat, Body Mass Index (BMI) and abdominal fat were measured using Omron Karada Scanner, meanwhile PACER test was used to measure cardiovascular endurance. The descriptive analysis showed, $71.67 \%$ Tamil school teachers from Kuala Selangor were found to be in the category of excessive body fat and obese. BMI levels, showed that $26.68 \%$ were overweight, $48.33 \%$ teachers were in level pre-obese till to obese stage III. Abdominal fat levels showed that $70 \%$ teachers were at risk. While only $20 \%$ of them having good cardiovascular fitness. The inferential analysis showed that there were significant differences in overall body fat and cardiovascular endurance between male and female subjects but BMI and abdominal fat levels showed no significant difference between male and female subjects. The findings indicated that most of the Tamil school teachers in Kuala Selangor District having high risk of cardiovascular diseases. They should do regular physical activity and consume balanced diet to reduce the risk of body fat and obesity which cause the cardiovascular diseases.
\end{abstract}

Author Correspondence, e-mail: gunathevan@fsskj.upsi.edu.my

doi: http://dx.doi.org/10.4314/jfas.v9i6s.85 
Keywords: Obesity, abdominal fat, total body fat, cardiovascular endurance \& physical activity

\section{INTRODUCTION}

Obesity is a major health problem in the world today. World Health Organization (WHO) [14], outlines that in 2014, more than 1.9 billion adults above 18 years of age, are overweight. Every year a total of 17 million people die due to cardiovascular diseases. This is an unhealthy development. Current conditions indicate that most malignant diseases occur as a result of unhealthy lifestyle practices. Thousands of Malaysians do not practice healthy lifestyle since their childhood. Working Malaysians do not care about the importance of taking breakfast. They do not take breakfast for many reasons such as no appetite in the morning and do not have time to prepare breakfast [3].

Healthy lifestyle should actually be practiced by every individual regardless of age and gender. If healthy lifestyle is not practiced, an individual may be vulnerable to illness, conflict and stress. According to [3], people in Malaysia are often exposed to various chronic health problems and eventually invite death. It is the result of unhealthy lifestyle practices and the imbalance of spiritual and physical health in daily life.

According to [1] and [14], obesity is the cause of chronic diseases such as cardiovascular diseases especially heart disease, stroke, diabetes and osteoarthritis. Obesity causes cardiovascular disease due to intra-abdominal fat and have a major impact on the metabolic process. This fat affects blood pressure, blood lipid levels and interferes with the ability to produce insulin effectively. Failure to produce adequate insulin, results in diabetes and cardiovascular diseases.

Abdominal fat is excessive fat around the internal organs and can have a negative effect on health. Abdominal fat exist for all ages regardless of age and gender. There is a strong correlation between abdominal fat, obesity and cardiovascular diseases [2]. These three problems cannot be underestimated because of their great impact on the health of an individual.

Cardiovascular endurance is an important component in physical fitness in relation to health. Components in cardiovascular system are heart, lung, blood vessels and muscles. The most 
important component of human physiological profile is $\mathrm{VO}^{2} \max$ which relates to the maximum oxygen utilization capacity of the body during physical activity. According to [9], exercise can improve the circulatory system, pumps blood faster at each heart beat and supplies more blood to the working muscles. Individuals whom perform regular physical activities increase their muscle strength, reduce body fat and maintain a healthy body mass.

In addition, dietary styles become the main cause of obesity due to an increase in fast food restaurants and food sales in packages or cans. Fast food restaurants such as KFC, Mcdonald and Pizza Hut have become favourites among Malaysians especially those who work because they do not have to bother to cook after day long tiring works. Although the food provided by this fast food restaurant is enriched and tasty, people should realize that taking this food should be reduced because the food is not nutritious and contains high levels of salt, sugar, and fat and that leads to overweight.

Statistics from National Health morbidity Survey [4], shows the prevalence of obesity among young people which causes cardiac related diseases increasing at young age compared to previous surveys. Heart related diseases which were found among those 40 years and above are now found among those in their twenties. Obesity problems do not choose individuals by age, gender, ethnicity, educational status, residential location, occupation and so on. It relies heavily on every individual's attitudes.

The Tamil school teachers from Kuala Selangor District not an exception to this phenomenon. While they are actively engaged in duties, the threats of various diseases caused by the problems of excessive body fat continue to haunt their souls. Tamil school teachers from Kuala Selangor District are suffering from obesity related problems and face the risk of various cardiovascular diseases. Accumulation of fat in the abdomen is clearly visible from their bloated stomachs and stomachs that look larger than their body shape. Teachers who are obese, overweight and a weak status of cardiovascular endurance would directly face difficulties in their daily activities of climbing up or down stairs, walking and so on.

The study focused on body fat, body mass index and abdominal fat and cardiovascular endurance. The purpose is to identify the current status of health components based on gender among Tamil school teachers from Kuala Selangor. The results of this study also aims to create awareness on the importance of healthy lifestyles, balanced nutritional practices and the 
risk of various illnesses that may be occurring at a young age to the teachers. Tamil school teachers from Kuala Selangor will be aware and be able to predict the level of their risks of getting cardiovascular diseases. Additionally, this study is also expected to assist them to take follow-up action and plan an effective strategy or develop a balanced nutrition-related programs aimed at improving the nutrition and health status.

The report released by the National Health Morbidity Survey [5] shows that 5.4 million adults aged 18 and above are categorized as pre-obese and 4.4 million are obese. A total of 0.3 million children under the age of 18 are in the category of obese. Meanwhile, the National Health Morbidity Survey report [6], shows that 3.5 million adults aged 18 and above have diabetes, 6.1 million have hypertension and 9.6 million (47.7\%) experiencing hypercholesterolemia. Furthermore, a total of 5.6 million are categorized as pre obese and 3.3 million are obese. Based on the definition of IPAQ, a total of 14 million Malaysians, that is $66.5 \%$ of the 16-year-old and above were physically active but failed to prevent various illnesses caused by sedentary lifestyles. Based on both studies conducted by the Ministry of Health, researchers have concluded that obesity, cholesterol levels in blood and diabetes are increasing year by year. Although the government is taking various preventative measures, the increase is still out of control.

[10] Have conducted a long-term study of 18 years to see the involvement in sports, fitness and health status among 723 men and women aged 28 to 76 in Germany. The results showed that the level of fitness and health status declined as age increased. Involvement in physical activity and sports also diminishes with time passage. This study also demonstrates a significant relationship between physical activity and fitness levels and health status. The researcher also suggested that physical activity that is unplanned and without specific purpose will not give any benefit in everyday life. It can be said that moving limbs aimlessly and determining appropriate activities is useless, though spending more than 30 minutes at least three (3) times a week.

Involvement in physical activity does not necessarily occur outside the home or in a special place for sports and leisure.[8], introduced physical activity at home to 13 breast cancer patients in Italy. All study participants conducted 40 days of those physical activities without the researcher's supervision. The results of the study proved increased cardiovascular 
endurance and muscle strength of the hands as well as decreased Body Mass Index. Although the difference between pre and post-test is relatively low, the effect can be seen clearly. If the exercise continues on a daily basis, a more positive effect on the immediate recovery of the disease will be seen. Based on this research, the researcher is able to state that Malaysian society should also be exposed to physical activities that can be done at home. This is because most women in our country often say that there is no time to go out for sports. Therefore, home-based training programs, as applied by these researchers, should be practiced in Malaysia although women here do not have any disease.

This study is a quantitative survey. The subjects of the study ware the Tamil school teachers in Kuala Selangor District from Selangor. Researchers conducted a survey among 60 teachers. 24 men and 36 women. The subjects voluntarily participated in this study. The research instrument is Omron Karada Scanner to measure the body's percentage of body mass index, amount of body fat and amount of abdominal fat. PACER tests were carried out to assess the degree of cardiovascular endurance. Descriptive analysis is used to get the status of health and to identify the risks of various illnesses experienced by Tamil school teachers from Kuala Selangor. For inferential analysis Independent samples $t$-test was carried out to see the differences that exist between the male and female subjects. Significant values were set at the significance level $\rho=0.05$.

\section{RESULTS AND DISCUSSION}

Based on the descriptive analysis, $31.67 \%$ of the male and $40 \%$ of female Tamil school teachers from Kuala Selangor were found to be in the category of excessive body fat and ,obese (Table I). BMI levels according to [11], showed that 5\% of men and $21.68 \%$ of women were overweight, $26.67 \%$ men and $21.66 \%$ female teachers were in level pre-obese till to obese stage III (Table 2). Abdominal fat levels showed that $26.67 \%$ of men and $43.33 \%$ of women were at risk (Table 3). While the level of cardiovascular endurance showed that $20 \%$ of men and $23.33 \%$ of women having moderate cardiovascular fitness and $16.67 \%$ of men and $25.00 \%$ of women in lower level (Table 4$)$. 
Table 1. Body Fat Levels

\begin{tabular}{lcccc}
\hline & \multicolumn{2}{c}{ Male } & \multicolumn{2}{c}{ Female } \\
\cline { 2 - 5 } & Total & Percentage & Total & Percentage \\
& & $(\%)$ & & $(\%)$ \\
Low fat & 0 & 0 & 0 & 0 \\
Normal & 5 & 8.33 & 12 & 20.00 \\
Excessive fat & 9 & 15.00 & 10 & 16.67 \\
Obese & 10 & 16.67 & 14 & 23.33 \\
Total & $\mathbf{2 4}$ & $\mathbf{4 0 . 0 0}$ & $\mathbf{3 6}$ & $\mathbf{6 0 . 0 0}$ \\
\hline
\end{tabular}

Table 2. BMI Levels according to WHO 1998

\begin{tabular}{llccc}
\hline & \multicolumn{2}{c}{ Male } & \multicolumn{2}{c}{ Female } \\
\cline { 2 - 5 } Total & Percentage (\%) & Total & Percentage (\%) \\
Underweight & 0 & 0 & 2 & 3.33 \\
Normal weight & 5 & 8.33 & 8 & 13.33 \\
Overweight & 3 & 5.00 & 13 & 21.68 \\
Pre-obesity & 10 & 16.67 & 6 & 10.00 \\
Obesity I & 3 & 5.00 & 2 & 3.33 \\
Obesity II & 2 & 3.33 & 3 & 5.00 \\
Obesity III & 1 & 1.67 & 2 & 3.33 \\
Total & $\mathbf{2 4}$ & $\mathbf{4 0 . 0 0}$ & $\mathbf{3 6}$ & $\mathbf{6 0 . 0 0}$ \\
\hline
\end{tabular}


Table 3. Abdominal Fat Levels according to WHO 2004

\begin{tabular}{lcccc}
\hline & \multicolumn{2}{c}{ Male } & \multicolumn{2}{c}{ Female } \\
\cline { 2 - 5 } & Total & Percentage & Total & Percentage \\
& & $(\%)$ & & $(\%)$ \\
Normal & 8 & 13.33 & 10 & 16.67 \\
\hline High & $\mathbf{1 0}$ & $\mathbf{1 6 . 6 7}$ & $\mathbf{1 5}$ & $\mathbf{2 5 . 0 0}$ \\
\hline Very High & 6 & 10.00 & 11 & 18.33 \\
Total & $\mathbf{2 4}$ & $\mathbf{4 0 . 0 0}$ & $\mathbf{3 6}$ & $\mathbf{6 0 . 0 0}$ \\
\hline
\end{tabular}

Table 4. Cardiovascular Endurance Level

\begin{tabular}{lcccc}
\hline & \multicolumn{2}{c}{ Male } & \multicolumn{2}{c}{ Female } \\
\cline { 2 - 5 } & Total & Percentage & Total & Percentage \\
& & $(\%)$ & 1 & $(\%)$ \\
A (Excellent) & 0 & 0 & 3 & 1.67 \\
B (High) & 2 & 3.33 & 14 & 5.00 \\
C (Moderate) & 12 & 20.00 & 15 & 23.33 \\
D (Low) & 10 & 16.67 & 3 & 25.00 \\
E(Very Low) & 0 & 0 & $\mathbf{3 6}$ & 5.00 \\
Total & $\mathbf{2 4}$ & $\mathbf{4 0 . 0 0}$ & $\mathbf{6 0 . 0 0}$ \\
\hline
\end{tabular}

Inferential analysis showed no significant difference in BMI levels between male and female $(p=0.671)$. In the researcher's view, the level of obesity among the Tamil school teachers from Kuala Selangor is almost the same regardless of gender because involvement in physical activity is somehow less for both gender. Nutrition patterns are also quite similar among Malaysian society. However [3], argues that gender affects obesity because the attitude and practice of healthy lifestyles play an important role in this phenomenon.

Abdominal fat between men and women showed no significant difference $(p=0.140)$. This is because abdominal fat exists in all age groups and gender. Generally, intra-abdominal fat poses a major health risk as there is a strong correlation between abdominal fat, obesity and 
cardiovascular diseases [14]. Cardiovascular endurance and overall body fat content between men and women showed a significant difference $(\mathrm{p}=0.000)$. [7], states that $\mathrm{VO}^{2} \mathrm{max}$ differences between men and women are influenced by differences in body composition and concentration of haemoglobin. However, women's aerobic capacity is generally higher than men with sedentary lifestyle.

\section{CONCLUSION}

The findings can be summarized that the risk of cardiovascular diseases among most of the Tamil school teachers from Kuala Selangor is alarming. Therefore, efforts to address this problem need to be implemented urgently to reduce the level of obesity and abdominal fat. At the same time the cardiovascular endurance level showed most of the Tamil school teachers from Kuala Selangor, not aware the risk and must take preventing care of themselves. The findings also found that teachers experiencing obesity problems were less conscious on the need to apply a healthy lifestyle in their daily lives. In view of this, it is hoped that teachers will be more sensitive to healthy lifestyle practices in their efforts to reduce their obesity and become a roll model for their students.

In conclusion, the individuals needs to play an important role in reducing the level of obesity. Everyone needs to be aware of the amount of calories consumed in daily diet. In addition, physical activity, healthy lifestyle and nutritional factors should also be taken into account in order to reduce obesity and weight problems. Continuous efforts and knowledge on nutrition and healthy lifestyle will have a good impact on our own well-being.

\section{REFERENCE}

[1] Chandrasekharan Nair Kesavachandran The normal range of body mass index with high body fat percentage among male residents of Lucknow City in north India, Indian J. Med Res., 2012, 135, 72-77

[2] Gunathevan, E., Norkhalid, S, Izwan, S. Mohanasundar, S, Dinesh, C. (2014). The Obesity Level And Abdominal Fat Among A Rural Tamil School Students in Malaysia. Universiti Pendidikan Sultan Idris. Best Journal., 2014, 2(1), 12-18 
[3] K. Umamaheswari*, Y. Dhanalakshmi, S. Karthik, Nitin Ashok John and Rehena Sultana, Effect of Exercise Intensity on Body Composition in Overweight and Obese Individuals. Indian Journal of Physiol Pharmacol, 2017, 61(1), 58-64

[4] Ministry of Health, National Health Morbidity Survey Report, (NHMS II), 2006, 4-13

[5] Ministry of Health, National Health Morbidity Survey Report, (NHMS III), 2011, 6-15

[6] Ministry of Health, National Health Morbidity Survey Report, (NHMS IV) 2015, 8-20

[7] McArdle, D.M. Katch, F.I. and Katch, V.L. Exercise Physiology: Energy, Nutrition and Human Performance. (4 th ed.). Philadelphia, PA: Lippincott. Williams and Wilkins, 1996.

[8] Mascherini,G, Giannelli, C, Ghelarducci, G, Degl'innocenti, S, Petri. C, \& Galanti. G. Active lifestyle promotion with home-based exercise in breast cancer Survivors, 2017, 12(1), 119-128

[9] Santu Dhara \& Kallol Chatterjee, A study of $\mathrm{VO}^{2} \mathrm{max}$ in relation with body mass index (BMI) of physical education students. Research Journal of Physical Education Sciences, 2015, $3(6), 9-12$

[10] Schmidt, S., Tittlbach, S., Bös, K. \& Woll, A. 2017. doi:10.1155/2017/1785217

[11] WHO, Obesity : preventing and Managing the Global Epidemic. Report of WHO Consultation on Obesity. Geneva: World Health Organization, 1998.

[12] WHO, Expert consultation. Appropriate body mass index for Asian populations and its implications for policy and intervention strategies. Geneva: World Health Organization, 2004. [13] WHO, Obesity : preventing and Managing the Global Epidemic. Report of WHO Consultation on Obesity. Geneva: World Health Organization, 2010.

[14] WHO, World Health Statistic 2014. World Health Organization. Geneva, 2014

\section{How to cite this article:}

Elumalai G, Hashim A, Shahril M I, Salimin N, Abadi F H. Body fat and risk of cardiovascular diseases among the tamil school teachers in kuala selangor, selangor. J. Fundam. Appl. Sci., 2017, 9(6S), 1152-1160. 